\title{
Mental health promotion in the wake of natural disaster
}

\section{Considerations for Hurricane Matthew victims based on historical precedent, Hurricane Katrina}

\author{
Lilian J. Robinson, Hong Yu (Andrew) Su \\ Faculty Reviewer: Lloy Wylie, PhD (Western Centre for Public Health and Family Medicine)
}

\section{ABSTRACT}

Significant psychological trauma to victims is an unavoidable by-product of severe natural disasters, and Hurricane Matthew is no exception. Making landfall on the 4th of October 2016, it swept across Haiti and eastern Cuba before reaching coastal regions of Florida, Georgia, and South Carolina. Despite Matthew's far-reaching impact, it was in Haiti where the Category Four hurricane made its greatest mark. Infrastructure damage led to water contamination and cholera outbreaks, sparking major concern amongst the World Health Organization and Haitian Ministry of Health. Consequently, physical health impact related to cholera control through clean water access was prioritized over psychological repercussions. In this article, we aim to provide recommendations for local organizations to deliver effectively psychological intervention to Haitian victims of Matthew. We focused on Global Trauma Research, one of few humanitarian agencies with an established framework for implementing psychological trauma relief efforts, and wish to use it as the basis of our suggestions. In order to do so, we chose to review mental health promotion in the context of a relevant historical precedent, Hurricane Katrina. We uncovered a two-pronged approach taken by Hurricane Katrina responders: identification of at-risk groups followed by provision of targeted-relief efforts, and widespread delivery of care to all affected populations, with an emphasis on community reintegration. Based on these general principles, we recommend that Global Trauma Research identify groups at risk of long-term emotional disturbance, provide relief in a targeted fashion on the basis of relative need, and place emphasis on Haitian citizen support through relocation and community integration.

\section{INTRODUCTION}

In the aftermath of Hurricane Matthew, the world turned their attention to Haiti, where high winds and heavy rains ravished infrastructure and crops, leaving up to 175,000 people in municipal shelters and more than 370 people dead. ${ }^{1,2}$ Potential resurgence of a pre-existing cholera epidemic was of primary concern as mixing of sewage with floodwater threatened clean water access across Haiti, a country still not fully recovered from the 2010 earthquake., ${ }^{2,3}$ Reports have put the total number of new cholera cases at 200 per day, up from 75 prior to Matthew's arrival. ${ }^{3}$ Proposed vaccination programs, along with the long-term restoration of infrastructure and provision of safe drinking water, are bound to require extensive financial resources. Comparatively less clear at this time is the way in which humanitarian agencies plan to address mental health and how they will implement necessary psychosocial supports to Hurricane Matthew victims.

For instance, The Canadian Red Cross provided widespread shelter, delivered water purification kits to support local emergency efforts, and deployed their own mobile Emergency Health Clinic. ${ }^{4}$ Likewise, World Vision speaks of 'meeting top needs', where top needs include water and sanitation, shelter, and food distribution throughout Haiti. ${ }^{5}$ Indeed, physical health is essential: when life is threatened, adequately resourced organizations must respond accordingly to prevent loss of life and restore health. It remains to be seen, however, whether humanitarian organizations such as The Canadian Red Cross and World Vision will engage in concomitant efforts to provide psychiatric first aid and mitigate the development of disaster-related psychiatric morbidities among Hurricane Matthew survivors.

As such, we have chosen to analyze a relevant historical precedent, Hurricane Katrina, in order to make informed recommendations about mental health promotion in Haiti following Hurricane Matthew.

\section{SELECTION OF HISTORICAL PRECEDENT}

Hurricane Katrina is selected for its similarity to Hurricane Matthew. Common factors of consideration included high disaster impact, extensive loss of infrastructure, loss of potable water access, displacement, prolonged threats to physical health, and loss of life. ${ }^{\circ}$ Given that no two disasters are equal, there are sure to be inherent differences. Indeed, Hurricane Matthew poses unique threats to public health that cannot be seamlessly replicated. Regardless, Hurricane Katrina may prove to be a rich source of knowledge for the application of mental health promotion in areas of Haiti affected by Hurricane Matthew.

\section{EXPERIENCE OF HURRICANE KATRINA AND SUBSEQUENT MENTAL HEALTH PROMOTION}

Hurricane Katrina struck New Orleans on August 29th, 2005. In addition to flooding more than 80 percent of the city, it claimed approximately 2,000 lives ${ }^{6}$ and displaced over 600,000 households across the Gulf Coast. ${ }^{7}$ In a similar fashion to Hurricane Matthew, which appears to have impacted impoverished, cholera-stricken regions of Haiti more heavily than developed regions in the United States, ${ }^{1-3}$ Hurricane Katrina is known for its disproportionate impact on African-American citizens of New Orleans. Socioeconomic factors such as poor living conditions, ${ }^{6}$ lack of transportation, ${ }^{8}$ and 
a lower pre-hurricane income, ${ }^{8}$ left impoverished members of the African-American population vulnerable and more likely to suffer from mental illness compared to higher income counterparts. ${ }^{6,8}$ Additionally, among children and adolescents exposed to hurricane-related stressors, those living in poverty were found at greater risk of developing sustained emotional disturbances, including post-traumatic stress disorder (PTSD), behavioural disorders, and other diagnosable forms of mental illness. ${ }^{9}$

Given this, subsequent mental health promotion strategies appear to have been aptly targeted towards at-risk populations. ${ }^{10}$ For instance, a trauma team from Louisiana State University Health Sciences Center (LSUHSC) provided outreach to children and families both in the immediate aftermath of Katrina and later in re-established school settings. ${ }^{10}$ In this case, intervention strategies were tailored based on age and individual perception of disaster. ${ }^{10}$ However, Katrina undoubtedly impacted victims of all socioeconomic backgrounds and of all ages. Therefore, in addition to the needsbased implementation of targeted relief efforts, mental health services were provided across all affected areas.

Response teams deployed by the Arkansas Chapter of the National Association of Social Workers (NASW-AR) proved especially integral in meeting the widespread mental health needs of Katrina survivors. ${ }^{11}$ Developed to respond to bioterrorism and pandemic events, interprofessional NASW-AR teams were called upon to design and deliver three levels of service across Katrina-affected regions: micro-, mezzo-, and macro-level services. ${ }^{11}$ These responses are, correspondingly, an eight-step psychological first aid intervention, connection of survivors with mental health service providers, and long-term assessment of loss and trauma followed by assistance with community integration. ${ }^{11}$

Hurricane Katrina literature is extensive. As such, the aforementioned examples represent only some of the ways in which humanitarian agencies and countless response teams rose to meet the needs of those affected. In the following section, we examine and apply known mental health responses in relation to Hurricane Katrina, in order to inform mental health promotion in the context of Hurricane Matthew and other global disasters.

\section{APPLICATION TO HURRICANE MATTHEW}

One organization of note, Global Trauma Research (GTR), has established a preliminary report detailing both their ongoing and planned responses to Hurricane Matthew. ${ }^{12}$ In the initial aftermath, GTR provided psychological first aid in multiple regions in Southern Haiti. ${ }^{13}$ Subsequent support focused on promoting anxiety management and stress mitigation. ${ }^{13}$ Finally, in the third and final stage of support, which is projected to last several years, GTR aims to train local mental health professionals who will provide ongoing resources to those in need. ${ }^{13}$

Intriguingly, the acute, intermediate, and ongoing stages of response outlined by GTR are comparable to the micro-, mezzo-, and macro-level services provided by NASW-AR teams in the aftermath of Hurricane Katrina. ${ }^{11}$ During this time, NASW-AR teams delivered widespread mental health relief to victims of Katrina. ${ }^{11}$ In this con- text, however, ubiquitous delivery of care by NASW-AR teams was necessary but not sufficient: in addition to providing widespread mental health care, organizations such as LSUHSC delivered psychosocial intervention to at-risk populations on the basis of relative need. ${ }^{10}$ Given the parallel natures of NASW-AR and GTR, we recognize the potential for GTR to engage in the non-specific delivery of care. We don't completely agree with this approach and suggest instead that GTR conduct a more thorough prospective assessment of Hurricane Matthew victims to identify most at-risk populations. While it is too early to assess the incidence and severity of lasting emotional disturbance amongst Hurricane Matthew survivors, historical precedent tells us that psychiatric morbidity should be elevated among more vulnerable populations. Lessons from Hurricane Katrina tell us that factors such as poverty, pre-existing illness, isolation from resources and cholera-based geography may all contribute to greater vulnerability. Once predisposing factors and corresponding at-risk groups are identified by GTR, their disaster mental health response strategies should shift accordingly.

Finally, missing from GTR's plan but present in plans carried out by LSUHSC and NASW-AR is an emphasis on reintegration. It bears mention that community integration, despite being emphasized in the context of Hurricane Katrina, left much to be desired. In fact, $61 \%$ of relief providers felt that local governments had not done enough to help Katrina survivors within their communities, and $79 \%$ reported likewise for federal governments. ${ }^{14}$ The same providers identified a number of barriers to psychosocial well-being, including integration into new communities, re-establishing transportation, finding affordable housing, and obtaining employment. ${ }^{18}$ These findings suggest ample room for improvement. Already, GTR strongly emphasizes cultural competency, which we believe to be a positive factor in the quest for successful community integration. We suggest that GTR amend their third and final stage of ongoing treatment to include focused efforts on community integration. What these efforts entail should be informed by both historical precedent and reputable academic literature.

\section{CONCLUSION}

Historically, agents of global health promotion have placed disproportionate emphasis on the promotion of physical health. ${ }^{15-19}$ This practice alone proves insufficient to alleviate the concerns natural disaster victims, who are commonly found to experience distress and grief,, ${ }^{21}$ anxiety disorders, ${ }^{19,20}$ PTSD, ${ }^{20,21}$ and major depressive disorder ${ }^{20}$ among others. Thanks to a growing body of literature supporting the link between disaster and mental health, patterns of humanitarian aid have shifted in response.

Response to Hurricane Katrina is evidence of the increasing emphasis that governments and humanitarian organizations now place on mental health promotion amongst disaster victims. Today, in the wake of Hurricane Matthew, Haitian victims in particular require deployment of mental health resources and psychosocial supports. Currently, the non-profit organization Global Trauma Research is working to provide acute and long term psychological intervention to Matthew survivors. Having analyzed mental health 
promotion in the context of Hurricane Katrina, we suggest that GTR place emphasis on the concurrent delivery of both widespread and targeted mental health services. In addition, in the months and years to come, we encourage GTR and other humanitarian agencies to introduce and apply culturally competent community integration, in the hopes of addressing the social supports required to normalize daily living and combat ongoing psychological distress amongst displaced people in a post-disaster context.

\section{REFERENCES}

1. The Weather Channel [Internet]. Atlanta (GA); c2016. Hurricane Matthew recap: destruction from the Caribbean states; 2016 Oct [cited 2016 Nov 25]. Available from: https://weather.com/storms/hurricane/ news/hurricane-matthew-bahamas-florida-georgia-carolinas-forecast.

2. Ferreira S. Cholera threatens Haiti after Hurricane Matthew. BMJ. 2016 Oct; 355:i5516.

3. Beaubien J. Haiti launches largest-ever cholera vaccination campaign. ProQuest [Internet]. 2016 Nov [cited 2016 Nov 25]. Available from: http://search.proquest.com.proxyl.lib.uwo.ca/ docview/1837449887?pq-origsite $=$ summon $\&$ accountid $=15115$.

4. Canadian Red Cross [Internet]. Ottawa (ON): Canadian Red Cross; c1996-2016. Hurricane Matthew response 2016; 2016 [cited 2016 Nov 27]. Available from: http://www.redcross.ca/how-we-help/current-emergency-responses/hurricane-matthew\#.

5. World Vision [Internet]. London (UK): World Vision International; c2016. Hurricane Mathew: responding to Haiti devastation; 2016 Oct [cited 2016 Nov 27]. Available from: https://www.worldvision.org/ disaster-response-news-stories/haiti-hurricane-matthew-response.

6. History [Internet]. Toronto (ON): Hurricane Katrina: 10 years later; c2015 [cited 2016 Nov 26]. Available from: http://www.history.com/ topics/hurricane-katrina.

7. Plyer A. Facts for features: Katrina impact. The Data Center [Internet]. New Orleans (LA): The Data Center; 2016 Aug [cited 2016 Nov 25]. Available from: http://www.datacenterresearch.org/data-resources/ katrina/facts-for-impact/.

8. Rhodes J, Chan C. The impact of Hurricane Katrina on the mental and physical health of low-income parents in New Orleans. Am J Orthopyschiatry. 2010 Apr; 80(2): 237-47.

9. Mclaughlin KA, Fairbank JA, Gruber MJ, Jones RT, Lakoma MD, Pfefferbaum B, Sampsom NA, Kessler RC. Serious emotional disturbance among youths exposed to Hurricane Katrina 2 years postdisaster. J Am Acad Child Adolesc Psychiatry. 2009 Nov; 48(11): 1069-78.

10. Speier AH, Osofsky JD, Osofsky HJ. Lifespan perspectives on natural disasters: coping with Katrina, Rita, and other storms. New York (NY): Springer Verlag; 2009 Jan. Chapter 12, Building a disaster mental health response to a catastrophic event: Louisiana and Hurricane Katrina; p 241-60.

11. Hoffpauir SA, Woodruff LA. Effective mental health response to catastrophic events: lessons learned from Katrina. 2008 Jan; 31(1): 17-22.

12. Global Trauma Research [Internet]. Global Trauma Research Inc.; c2013. Who we are; c2013 [cited 2016 Nov 27]. Available from: http:// www.gtrinc.org/about.html.

13. Global Trauma Research Inc.'s Haiti trauma project / hurricane relief preliminary report [Internet]. Global Trauma Research; 2016 Oct 23 [cited 2015 Nov 27]. Available from: http://nebula.wsimg.com/ e90a9a352ce7cd20c0bee7d779db3e83?AccessKeyId=ADB9A8F9472072C32915\&disposition=0\&alloworigin=1.
14. Dass-Brailsford P. Crisis and disaster counselling: lessons learned from Hurricane Katrina and other disasters. Thousand Oaks (CA): SAGE Publications; 2009. Chapter 7, Provider perspectives on serving the needs of displaced disaster survivors following Hurricane Katrina; $p$ 107.

15. Desjarlais R, Eisenberg L, Good B, Kleinman A. World mental health: problems and priorities in low income countries. New York (NY): Oxford University Press; 1995. Introduction; p 3.

16. Atlas: mental health resources in the world [Internet]. World Health Organization; c2001 [cited 2016 Nov 23]. Available from: http://www. who.int/mental_health/media/en/244.pdf.

17. Lavikainen J, Lahtinen E, Lehtinen V. Public health approach on mental health in Europe [Internet]. National Research and Development Centre for Welfare and Health, STAKES Ministry of Social Affairs and Health; c2000 [cited 2016 Nov 23]. Available from: http://ec.europa.eu/health/ph_projects/1998/promotion/fp_promotion_1998_ frep_11_c_en.pdf.

18. Jacka FN, Mykletun A, Berk M. Moving towards a population health approach to the primary prevention of common mental disorders. BMC Med. 2012 Nov; 10:149.

19. Tol WA, van Ommeren M. Evidence-based mental health and psychosocial support in humanitarian settings: gaps and opportunities. Evid Based Ment Health. 2012 May; 15(2):25-6.

20. Hussain A, Weisaeth L, Heir T. Psychiatric disorders and functional impairment among disaster victims after exposure to a natural disaster: a population based study. J Affect Disord. 2011 Jan; 128(1-2):135-41.

21. Yang YK, Yeh TL, Chen CC, Lee CK, Lee IH, Lee L, Jeffries KJ. Psychiatric morbidity and posttraumatic symptoms among earthquake victims in primary care clinics. Gen Hosp Psychiatry. 2003 Jul; 25(4): 253-61. 